\title{
首流振勤流れの助走距離 *
}

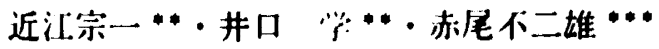 \\ Inlet Length in Oscillatory Laminar Duct Flow*
}

\author{
Munekazu Ohmi** • Manabu Iguchi** • Fujio Akao***
}

\begin{abstract}
Inlet length in an incompressible oscillatory laminar duct flow is studied. If a fluid particle which can reach farthest from a given cross-section of a duct of semi-infinite length reaches just the entrance from where it never goes out, any of the particles located in this cross-section has no concern with the entrance. Therefore. it is reasonable to define an inlet length in terms of the distance between this cross-section and the entrance. Calculations of inlet length were made for a circular duct and four kinds of rectangular ducts. The results show that the inlet length $L_{e}$ is a function of a Reynolds number based on the velocity amplitude of oscillation and of a dimensionless frequency for a circular duct and a function of these two parameters as well as the aspect ratio for a rectangular duct. The inlet length $L_{e}$ is directly proportional to the Reynolds number and inversely to the dimensionless frequency. The proportional constant $k$ was graphically shown for each duct.
\end{abstract}

\section{1. 緒 喑}

助走区間か問題となるような短い管路内の首流非定 常流れの特性を明らかにすることは油压機器の動特性 の評価にとって重要な問題の一つである。この分野の 研究で従来行なわれてきたものは, 流昷か過渡的に変 化する場合 ${ }^{1,2)}$ と逆流の生じない脈臐流れの場合に限 られている゙が,いずれも理論と実段の両面からかな り詳しく追求されて来た。最近の中野らいのの研究成 果か報告されるに及んて、これら二類の非定常流れ の特性はその全容がほほ理解されたといってよいであ ろう。ところで油压機器をはじめとする各種管路網に おいては，流れの方向か周期的に変化する場合がしば しば起こるか，このような流れ場の助走区間について 論じた報告は著者らの知るかきり見当らない。

著者らは層流振助流れと逆流を伴う届流脈動流れを 对象として助走区間内の圧力損失, 速度分布などの諸

\footnotetext{
- 昭和57年 9 月20日 原橋受付

* 大阪大学工学部

... 点工業高等尃門学校
}

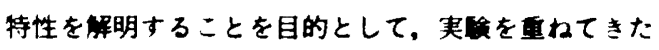
か、ここて対象とする管路の畏短の判断に对する基集

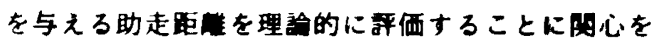
持った。本報告では、この評価法を提采し、円管と長 方形管について計結果を示すことにする。

\section{2. 部 号}

$$
\begin{aligned}
& a, b \text { : 長方形管路の唒と高さの半分 } \\
& D: \text { 管直径 } \\
& f: \text { 周波数 } \\
& k \text { : 軸方向速度 } u \text { の振幅| } u_{o x, 1} \mid \text { の最大值と断面 } \\
& \text { 平均速度 } u_{m} \text { の振幅 }\left|u_{m, 0,1}\right| \text { との比 } \\
& L_{e}: \text { 助走距 } \\
& R: \text { 管半径 } \\
& R_{e} \text { os }: \text { レイノルス数 }=D\left|u_{m, 0 s, 1}\right| / \nu \\
& R_{\text {e os }} \text { : ᄂイノルス数 }=2 b\left|u_{\text {mos. } 1}\right| / \nu \\
& r: \text { 半径方向座槙 } \\
& S: \text { ストローハル数 }=f \mathcal{D} /\left|u_{m, 0,1,}\right| \\
& S^{+}: \text {ストローハル数 }=2 b f /\left|u_{m, 0,1}\right| \\
& T: \text { 振動流九の周期 } \\
& t: \text { 時間 }
\end{aligned}
$$




\section{$\boldsymbol{u}$ ：由方向速度成分 \\ $\left|u_{o s, 1}\right|: u$ の基本波振幅 \\ $\gamma:$ 経松比 $\equiv a / b$

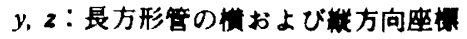 \\ $\nu$ ：助粘性保数 \\ $\omega$ : 层怔流れの角周波数 \\ $\omega$ : 策次元角用波数 $\equiv R^{2} \omega / \nu$ \\ $\omega^{+}$: 虍次元角周波数 $\equiv b^{2} \omega / \nu$ 添宇ほか \\ m: 管杪断面平均檤を衣す \\ os：掁野流れを表す

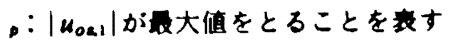 \\ 、基本波を衰す \\ 3. 助走距睢の定新と新算結果}

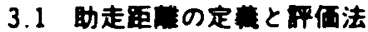

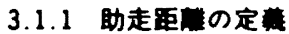

流体が平担な速度分布をもって半無限長の管内に入 ろ定常流れの坦合には，入口から棒面にそって管轴方 向に発達する境界居が管内を埋めつくした後，流れ場 が軸方向依存性を示さなくなったとき流れは十分発達 したといい, 助走距離については，例えば入口から中 心速度が十分発连したそれの99\%になった位面までの 距部て定義している”。しかしなからら、ここで対象とす ろ振動流れは時間平均成分のない交番流のことで り，管路入口近傍を占めている流体は半周期ごとに管 路に出入りすることになる.したかっって一方向流れの 場合とは異なり、どれたけの時間が経過しようとも， 少しでも入口の外に出た経非をもつ粒子は入口から定 まった距離までしか管内に到達することはできない。 この穊囲において，管内に入ってくる流れと出てゆく 流れとでは流れのパターンは大きく異なるか，それよ りも奥側の管内位置では両者のパターンは全く同じと なる.そして,この距傕は振動の周期と振幅によって 規定されるであろう。

ここに想いを巡らせば，振動流れにおける助走距踓 は，管路入口から外に出た経験をもつ粒子が管路内に 到達しうる朝方向最大距踓であると定義して十分合理 的であろう。しかしながら流体が管路に流入する場合 の運動を記述する方程式は非線形であって, 流体粒子 の移動経路を正確に把握することは不可能でないにし ても非常に難しい. 各種形状管路における振動流れの 助走距離が周波数や振幅の関数としてどのように記述 されるのかか今のところ分っていない理由の一つはこ こにあると思う。そこで,ここでは着眼点を変えて, 入口の影謷を受けない管内位置にある流体粒子の運的
から助走医湖定してみよっとナるものてあう。 入口の影ひ及ばない㫑方向位目においては，流れ は平行流となっており，流体粒子は一周期每に管为伷

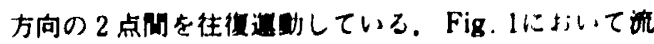
几の向、が右方から方へと变わったとき。ある所面

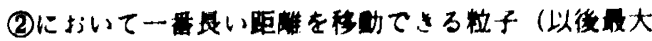

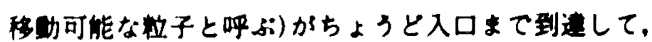
外、出ることなく㞔って来ることがてきたならば，こ の断面(2)にある柆子はどれてつとして管の外へ出ない

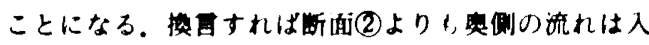
口の徰を全く受けないことになる。

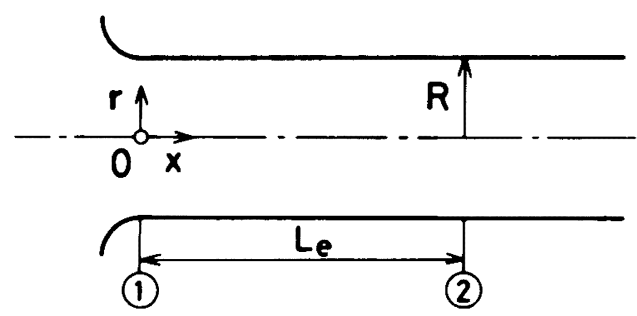

Fig. 1 Schematic of a circular pipe

ここで周波数が非常に低い場合，断面(2)において曼 大移功可能な粒子は管中心軸上を移動する粒子である か，この粒子がちょうど入口断面まで到逵したとき， これに際接して入口のすぐ外にある粒子は軸対称流れ の性筫に基づき，流れの逆檕後も前者の粒子に接しな がら管中心軸上を移動し，断面(2のすぐ手前まて送つ て来るはずである，また周波数が高くなると最大移期 可能な粒子の存在する半径位目は管中心から管壁側へ 移動するが，断面(2)においてこの粒子に接して入口側 にある粒子は，当然入口の外側へ出た経検をもつ粒子 であるはずである。したがって振助流れの助走距部は 入口(1)から断面(2)までの距離L。で与えられることに なる。たたし，周波数 $f$ か上記の低い周波数よりもさら に低くなって $f \rightarrow 0$ となる場合を考えると各瞬間の流 れは定常流れと同じになるために，入口から管内に 入っていく粒子は粘性の奻果が相対的に大きく奻いて くることによって管内て停止する以前のある軸方向位 置で入口の経硂を忘れてしまう。これを運動方程式に ついていえば，冒性力のうち非定常項が消隇してしま うことに対応する。このような場合には，当然のこと ながら，前述の考えに従って定義したL：は適用でき ない.したがって、ここでは $f \fallingdotseq 0$ を除外し，項性力の うち非定常項と対流項のいずれも無視できない場合を 取扱うことにする．これを条件式で示せば $R_{e}$ os $R_{e}$ os

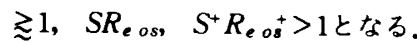




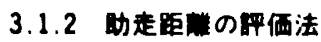

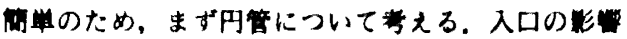
つ及ばない舳方向断面内て任意の半往方向位俉に扔け

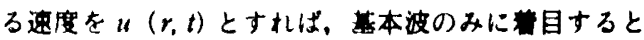
$*$

$$
u(r, t)=\left|\|_{t, n, t}(r)\right| \sin \omega t
$$

と衰される。そして柆子の移影距離 $L(r)$ は次式で与 えられる。

$$
L(r)=\int_{0}^{r / 2} u(r, t) d t
$$

ここて $T$ は振野缃期てある。式(2)は各半径位目にある

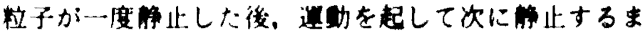
ての距離を表すことになる。

前節の定我に従夫ば，助走距噰 $L$ は～$L(r)$ の最大值

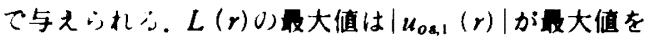

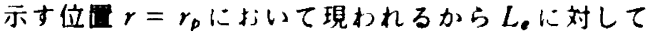
次式を得る。

$$
\begin{aligned}
L_{e} & =\left|u_{o s .1}\left(r_{p}\right)\right| \int_{0}^{T / 2} \sin \omega t d t \\
& =(2 / \omega)\left|u_{o s .1}\left(r_{p}\right)\right| \quad \ldots .
\end{aligned}
$$

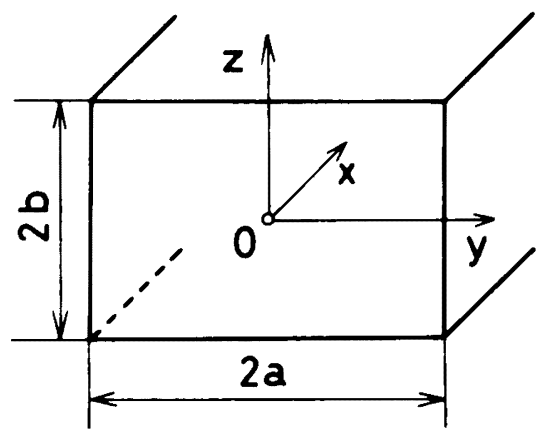

Fig. 2 Schematic of a rectangular duct

長方形管（平行平板を含む）の場合には座栖系を Fig. 2 の上うにとったとき, 式(3)の $\left|u_{o s, 1}\left(r_{p}\right)\right|$ を| $u_{o s, 1}\left(y_{p}\right.$ $\left.z_{p}\right) \mid て ゙$ 置きかえればよい.ここで $\left(y_{p}, z_{p}\right)$ は| $u_{o s, 1}(y$, z)|が最大値を示すところの座栖である.

式(3)をレイノルス数と無次元角周波数を用いて変形 すれば円管に対しては次式

$$
\begin{aligned}
& L_{e} / D=k R_{\text {eos }} /\left(2 \omega^{\prime}\right) \\
& k=k\left(\sqrt{\omega^{\prime}}\right)=\left|u_{o s, 1}\left(r_{p}\right)\right| /\left|u_{m, o s, 1}\right| \\
& R_{\text {eos }}=D\left|u_{m, o s, 1}\right| / \nu \quad \ldots \ldots \ldots \ldots \ldots . . . \\
& \omega^{\prime}=R^{2} \omega / \nu
\end{aligned}
$$

が，長方形管に対しては次式が得られる.

$$
L_{e} /(2 b)=k R_{\text {eos }}^{+} /\left(2 \omega^{+}\right)
$$

$$
\begin{aligned}
& k=k\left(\sqrt{\omega^{+}}, \gamma\right)=\left|u_{\infty, 1}\left(y_{p}, z_{p}\right)\right| /\left|u_{m, \infty, 1}\right| \\
& R_{\text {eos }}^{+}=2 b\left|u_{m, 0 s, 1}\right| / \nu \\
& \omega^{+}=b^{2} \omega / \nu
\end{aligned}
$$

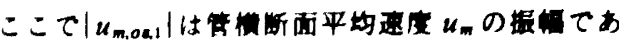
i.

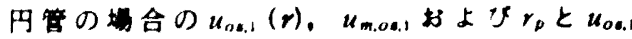

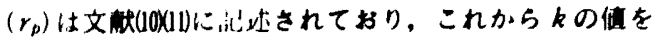
計算することがでる。展方形管（平行平饭を合し）

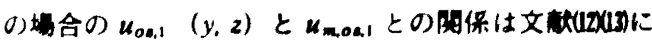

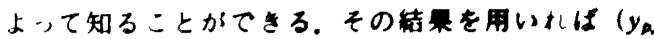
$\left.z_{p}\right)$ と $k$ の做が容易に求まる。

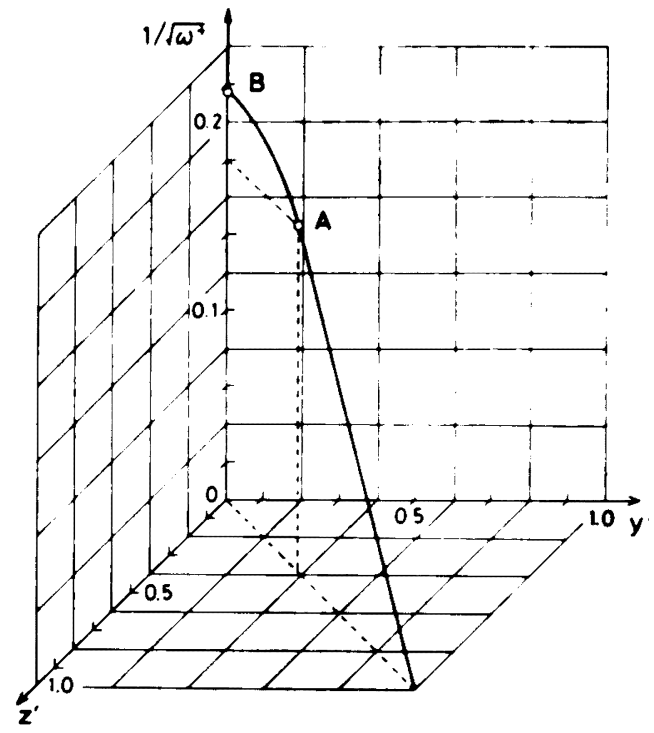

Fig. 3 Locus of $\left(y_{p}^{\prime}, z_{p}{ }^{\circ}\right)$ in a rectangular duct of $\gamma$ $=1$, where $y_{p}^{\prime}=y_{\alpha} / a$ and $z_{p^{\prime}}=z_{p} \cdot b$ $\mathrm{A}=(0.390,0.390,0.180), \mathrm{B}=(0,0$, $0.215)$

\section{2 計算桔果}

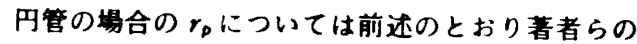
一部が以前に報告しているいのでここでは省略する。

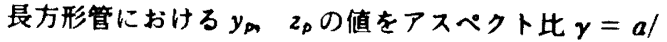
$b$ が 1，2，4，向場合に対して計算してみる上，そ れぞれ Fig. 3〜6に示したようになる.つぎに を一つの図にまとめてみると Fig.ていようになる。無 次元角周波数 $\omega^{\prime}$ あるいは $\omega^{+}$の值が小さくなると， $k$ の值は円管,長方形管のいずれの場合にも，それぞれ の管路内の定常流れで知られた値へと䉼近している。

一方， $\omega^{\prime}$ あるいは $\omega^{+}$の値が非常に大きくなると 任意の断面形状管内の流れは管内の大部分を占める一 


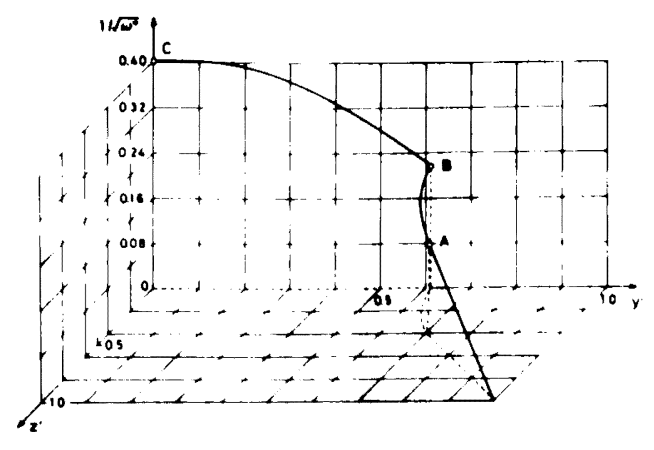

Fig. 4 Locus of $\left(y_{p}^{\prime}, z_{p}^{\prime}\right)$ in a rectangular duct of $\gamma$ $=2$

$\mathrm{A}=(0.698,0.396,0.176), \mathrm{B}=(0.623,0$, $0.220), \mathrm{C}=(0,0,0.408)$

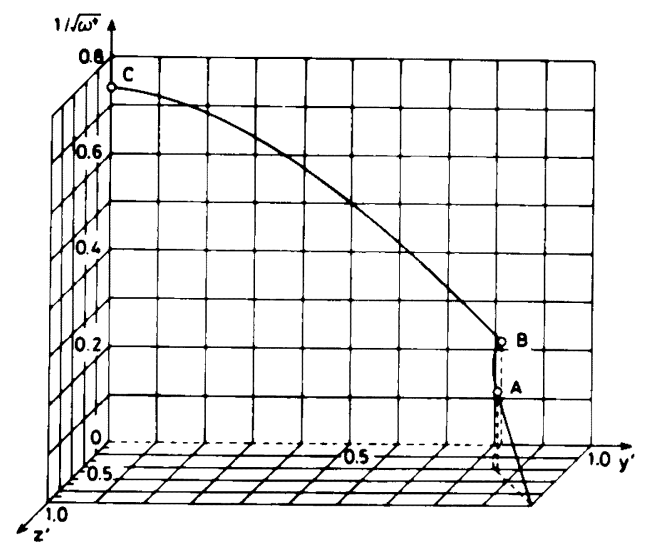

Fig. 5 Locus of $\left(y_{p}^{\prime}, z_{p}^{\prime}\right)$ in a rectangular duct of $\gamma$ $=4$

$\mathrm{A}=(0.862,0.448,0.164), \mathrm{B}=(0.811,0$, $0.220), \mathrm{C}=\left(\begin{array}{l}0,0,0.735) \\ -10\end{array}\right.$

様流と管壁をおおう境界届とから成立つことが知られ ている(4).ここで境界層内の速度分布は平板にそう振 動流れすなわちストークス首の速度分布 ${ }^{15)}$ と同じも のとなる、したがって円管, 長方形管のいずれの場合 にも無次元角周波数の增加とともに $k$ の值はストー クス首の值 $k \fallingdotseq 1.069$ へと渐近してゅくことになる.

円管と平行平板 $(\gamma=\infty)$ の場合には $\sqrt{\omega^{\prime}}, \sqrt{\omega^{+}} \fallingdotseq 100$ でストークス層の值にほほ一致してくる.

Fig.7によって $k$ の值を読み取り，式(4)，(6)に代入す れば振動流れの助走距離が評価できることになる。

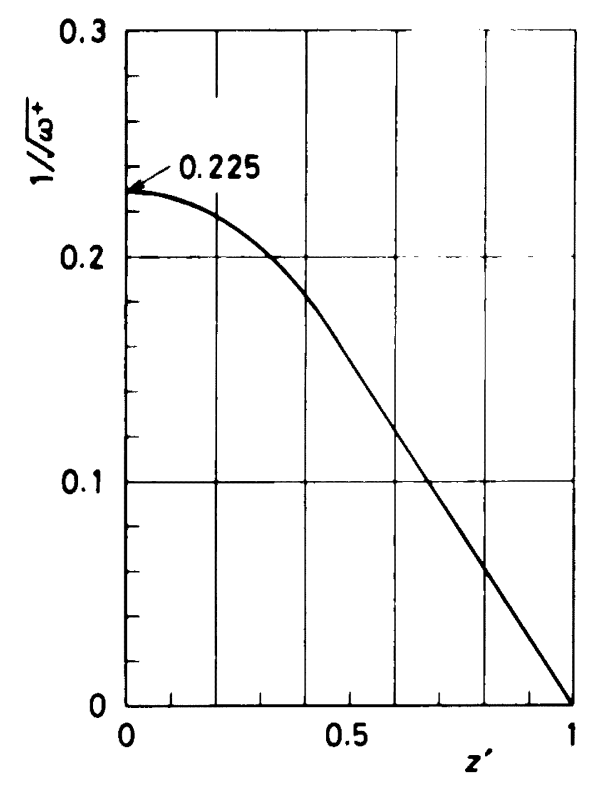

Fig. 6 Locus of $z_{p}^{\prime}$ between two parallel plates.

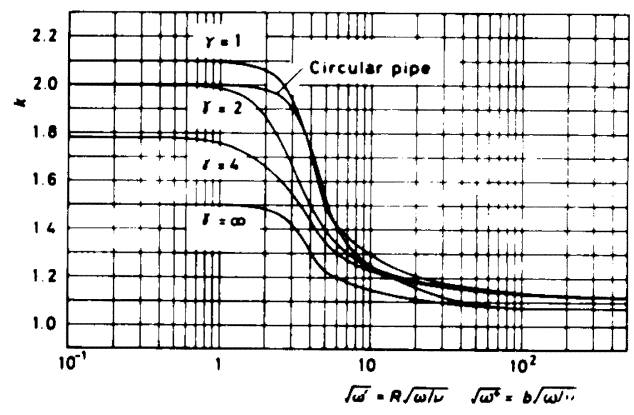

Fig. 7 Change in $k$ with dimensionless frequency

\section{4. 結 管}

半無限長の管内のある横断面位目に者目したとき, その断面内の流体粒子のうち最も遠くまで移動しうる 粒子がちょうど入口まで到達して外には出ないなら ば，その位置よりも奥側の横断面位置における全ての 流体粒子は決して管の外へ出ることはなく，入口の存 在を感知しないことになる。したがって，その位置か ら入口まての距離が助走距離 $L$ eであると定義して, これを円管と長方形管について計算した。助走距離 $L_{e}$ は円管に対しては $L_{e} / D=k R_{\text {e os }} /\left(2 \omega^{\prime}\right)$, 長方形管に 対しては $L_{e} /(2 b)=k R_{e} o^{+} /\left(2 \omega^{+}\right)$で表わされる. そして $k$ の值を計算して,これを Fig. 7にまとめ,管路 網設計上の基稳資料を提供した。 


\section{考文}

1) Avula, X. J. R: Analysis of suddenly started laminar flow in the entrance region of a circular tube, Appl. Sci. Res. 21, 248 259 (1969-10).

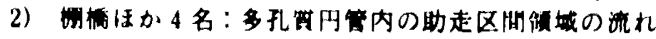

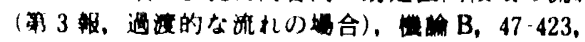
21312138 (昭56-11)。

3) Attabek, H. B. and Chang, C. C. : Oscillatory flow near the entry of a circular tube, ZAMP, XII, 185 201 (1961).

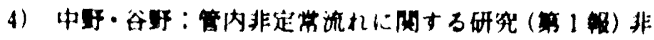

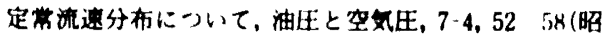
$51 \cdot 7)$.

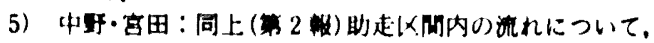
油压と空気圧, 8-1，60/66 (昭52-1).

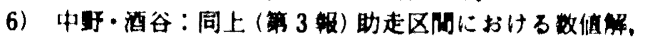
油压と空気死, 9-3，62，68(昭53-5).

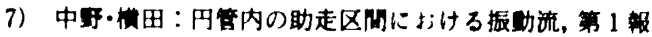
值解と实結果, 油压と空気压, 10-1，64／71(昭54 $-1)$.

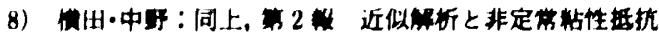
保议。油压と空気圧, 11-2, 41/48+56 (昭55-3).

9) Shah, R. K. and London, A. L. : Laminar flow forced convection in ducts, Advances in Heat Transfer, Supplement 1, Academic Press (1978).

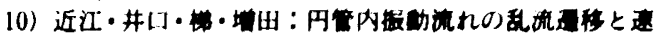

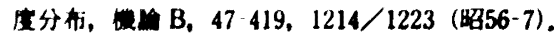

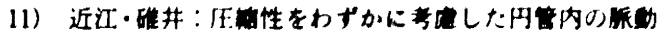

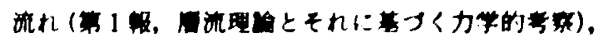
证的, 41-342, 546/558 (昭350-2).

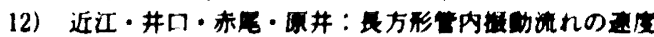

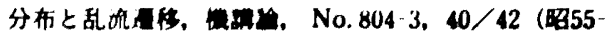
3).

13) Drake, D. G. : On the flow in a channel due to a periodic pressure gradient. Q. J. Mech. Appl. Math., $181,1 / 10$ (1965).

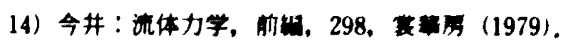

15) Schlichting. H. : Boundary Layer Theory, 6th ed., McGraw-Hill (1968). 